\title{
Positive Psychology Research in the Philippines: An Introduction
}

\author{
Jesus Alfonso D. Datu \\ The Education University of Hong Kong \\ Allan B. I. Bernardo \\ University of Macau \\ Ronnel B. King \\ The Education University of Hong Kong
}

Over the past two decades, advances in positive psychology has resulted in an exponential increase in the number of studies concentrating on the dispositional, interpersonal, and socio-contextual factors which can optimize adaptive psychological and well-being outcomes. However, most of these investigations have focused on expanding the science of positive traits, states, and institutions in Western cultural contexts. The generalizability and applicability of these Western models have to be scrutinized and reconsidered when they are transported to different cultural settings. There is also a need to come up with emic studies that closely reflect the lived experience of peoples across cultures.

In recent years, there has been a burgeoning interest in crosscultural studies that include samples from non-Western cultures including the Philippines (see Church et al., 2014; Kuppens, Realo, \& Diener, 2008; McGrath, 2015). There has been some noticeable increase in positive psychology research in Asian cultural contexts (see Caleon, King, et al., 2017; Caleon, Wui, et al., 2017; Duan, Ho, Tang, Li, \& Zhang, 2014; Kumano, 2018; Low, King, \& Caleon, 2016) including the Philippines (see King \& Datu, 2017; Mesurado, Richaud, \& Mateo, 2016; Rosopa, Datu, Robertson, \& Atkinson, 2016). Given the critical role that sociocultural factors play in shaping well-being and optimal functioning (Steel, Taras, Uggerslev, \& Bosco, 2018; Tov \& Diener, 2009), it is important to investigate how positive psychological factors can serve as either antecedents or consequences of optimal psychological functioning in specific cultural contexts. 
Much of the work in Asia has focused on positive psychological traits and states and their relationship to well-being outcomes in educational settings in Asia. Some of this research has been put together in a special journal issue on positive education in the Asian context (King, Caleon, Tan, \& Ye, 2016) that featured studies exploring different positive personal and sociocultural factors which could contribute to key learning outcomes among student populations in Hong Kong, Macau, Mainland China, Indonesia, Malaysia, Singapore, and the Philippines. The positive education research included from the Philippines explored the roles of positive affective states (Villavicencio \& Bernardo, 2016) and selected dispositional factors like psychological capital (Datu \& Valdez, 2016; Ganotice, Yeung, Beguina, \& Villarosa, 2016) and locus-of-hope (Bernardo, Salanga, Khan, \& Yeung, 2016) play in catalyzing desirable learning processes and outcomes among Filipino student and non-student populations. Most other published positive psychology research in the Philippines has focused on positive traits and character strengths as predictor of students' well-being, adjustment and learning outcomes (see Datu, King, \& Valdez, 2017, 2018; Datu, King, Valdez, \& Eala, 2018; Datu, Valdez, Cabrera, \& Salanga, 2017; King \& Datu, 2017; Magno, Galang, Paterno, \& Roldan, 2011), and this trend is reflected in the contents of this special issue.

However, there are also studies that delved into positive traits and states as predictors of various psychological outcomes of special populations such as survivors of natural disasters (Nalipay, Bernardo, \& Mordeno, 2016, 2017), and women who experiences intimate partner violence (Bernardo \& Estrellado, 2017a, 2017b); and also studies that look into predictors of well-being in special populations such as Moro National Liberation Front (a political organization of Muslim separatists) integrees (Redoble-Buot, 2006), abused children (Tarroja, Balajadia-Alcala, \& Co, 2007), children left behind by migrant parents (Bernardo, Tan-Mansukhani, \& Daganzo, in press; Graham \& Jordan, 2011) and overseas Filipino workers (Bernardo, Daganzo, \& Ocampo, 2016), and life satisfaction of older Filipino sexual minorities (Guevara, 2016).

Other published positive psychology studies in the Philippines involve validation of and descriptive studies using psychological scales associated with well-being in Filipino samples, like the Filipino translation of the Values in Action Inventory of Strengths (Resurreccion, 2017) and the Subjective Happiness Scale (Swami et al., 2009), or the original English versions of the Interdependent Happiness Scale (Datu, King, \& Valdez, 2016), and Satisfaction with Life Scales (Manalastas \& Mondragon, 2006). But a larger number involves studying social psychological correlates and predictors of 
various aspects of well-being (Bernardo, 2013; Chen, Bao, Shattuck, Borja, \& Gultiano, 2017; Datu \& Mateo, 2015; Edillo, Turiano, Reyes, \& Villanueva, 2012; Uchida, Kitayama, Mesquita, Reyes, \& Morling, 2008) or the how measures of well-being relate to other psychological outcomes like academic achievement (Datu \& Valdez, 2016; King, 2015), job satisfaction of elderly workers (De Guzman, Largo, Mandap, \& Munoz, 2014), work longevity of counselors (Datu \& Mateo, 2017) or help-seeking in women who experience intimate partner violence (Bernardo \& Estrellado, 2017a). Surprisingly, there are very few published studies that inquire into meanings associated with wellbeing of Filipinos (SyCip, Asis, \& Luna, 2000) and of specific special populations of Filipinos (e.g., chronically ill and incarcerated elderly Filipinos) (De Guzman et al., 2012). This is surprising given the strong interest in exploring meanings of psychological concepts using emic or indigenous psychological approaches. But it is also possible that such studies have been conducted but are currently unpublished, as are other positive psychology studies conducted by psychology students and researchers in various universities and research centers in the Philippines.

Although therehave been published research in positive psychology in the Philippines, there are still are a number of reasons that may point to the necessity of further cultivating positive psychology knowledge in the Philippines. First, the popularity of positive psychology in many parts of the world, including the Philippines, has opened the space for sharing pseudoscientific knowledge about positive psychological concepts. As with other psychological trends that have become fads, there is the danger of misappropriating some of the concepts and findings of the growing scientific subdiscipline of psychology in various domains of life. There are already people who advocate programs and interventions that purport to apply positive psychology, but actually misunderstand, misinterpret, or worse, bastardize the nuanced theoretical and empirical knowledge in positive psychology.

Second, amid the possibility of such misuse of positive psychological concepts, scientific research on positive psychology research in the Philippines could provide better guides to how to effectively apply positive psychological principles in the Philippine context. The need for these scientifically based applications seems particularly necessary given the growing stressors that threaten the psychological well-being of Filipinos. These stressors might relate to the intensifying background stressors of everyday traffic, pollution, work pressures in big cities, to the divisive political rhetoric and developments in contemporary Philippine society, to the uncertainties created by changes in economic and financial policies, to the malaise 
brought about by systematic spread of fake news and information, and to the pressures experienced by students, their families, teachers, and other education professionals related to the shift to the $\mathrm{K}$ to 12 education reforms, among others.

Third, there is a need to understand whether the theoretical principles and empirical findings established regarding how positive traits, states, and institutions are linked to happiness as well as other optimal psychological outcomes in non-Western and interdependent societies (e.g., Mainland China, Hong Kong, and Singapore), also predict happy and successful life in the Philippine context. Or perhaps, whether there are distinct models that apply to the experience of Filipinos.

Finally, there is a need to further study the appropriateness of the very basic premises of positive psychology to the Philippine experience. For instance, are the existing Western models of well-being (i.e., subjective well-being, psychological well-being, psychological flourishing) equally applicable to Filipino populations? This clearly points to the need to explore the lay conceptions of well-being in the Philippine setting. As suggested by some scholars (see Joshanloo, 2014; Tsai, 2007) Eastern cultures might have different conceptions of happiness and positive affective states. Moreover, some cultures might even be averse to the pursuit of happiness (Joshanloo \& Weijers, 2014). All these factors considered, there are many important reasons why we need more and better research on positive psychology in the Philippines.

These aforementioned reasons provide the motivation for this special issue on positive psychology research in the Philippines. The special issue hopes to push further, even in slight increments, the agenda of positive psychology that is based on sound scientific work. The special issue highlights the significance of adopting a 'positive psychological perspective' when designing empirical studies in the Philippine setting. In this regard, this special issue features five investigations exploring the association of positive personal qualities and states with like locus-of-hope, interdependent happiness, life satisfaction, and psychological thriving among Filipino student and non-student populations. The authors of these studies used either a quantitative and non-experimental design or a purely qualitative design to examine the advantageous side of espousing positive traits and experiencing positive subjective states among Filipino samples.

In the first study, Bernardo and Fernando-Resurreccion (2018) examined the moderating roles of external locus-of-hope ( $\mathrm{LOH})$ dimensions on the link between financial stress and well-being among university students. Consistent with their hypotheses, whereas 
financial stress negatively predicted well-being, all external locus-ofhope dimensions (i.e., family, peers, and spiritual) positively predicted the said outcome. Moreover, external-family LOH buffered the negative association of financial stress with well-being. Their investigation contributed to the existing line of evidence on the $\mathrm{LOH}$ theory through demonstrating the protective role of external $\mathrm{LOH}$ against the hazards of finance-related stress among undergraduate students.

The second research carried out by Datu and Lizada (2018) explored the link of interdependent happiness to different dimensions of academic engagement among university students from a rural context. The authors found that interdependent happiness positively predicted both behavioral and emotional engagement after controlling for demographic variables (i.e., age and gender). However, interdependent happiness did not predict behavioral and emotional disaffection. This investigation uniquely expanded the interdependent happiness literature through showing how interdependent happiness may be differentially related to various domains of school engagement.

Given that most studies conducted in the Philippine setting primarily focused on university and secondary school student populations, the third study of Mateo and Salanga (2018) assessed the association of life satisfaction with counseling self-efficacy, emotional awareness, and state flow among Filipino guidance counselors. Their investigation demonstrated that life satisfaction positively predicted emotional awareness and state flow even after controlling age, gender, civil status, and highest educational attainment. The authors' investigation expanded the line of evidence on how different wellbeing dimensions could predict work-related outcomes. This study also underpins the importance of fostering cognitive well-being among mental health professionals in the Philippine context.

The fourth investigation of Nalipay and Alfonso (2018) examined the link of self-compassion to hope as well as career and talent development self-efficacy among university students. This research showed that self-compassion positively predicted career and talent development self-efficacy. More importantly, self-compassion had indirect effects on career and talent development self-efficacy via the intermediate variable - hope. Their empirical study uniquely contributed to the extant literature on the psychological processes underpinning the link between self-compassion and self-efficacy outcomes especially in collectivist societies.

The last study of Buenconsejo (2018) explored the notion of psychological thriving via an interpretative phenomenological analysis among Filipino adolescents. The following major themes emerged in the study: (a) perception of the nature of spark; (b) family and social 
groups as providers of guidance and support; (c) religious spark as source of positive experiences; (d) religious spark as source of negative experiences; and (e) compromises and adjustments amidst constancy of spark. This investigation extended the theorizing of psychological thriving or 'spark' in the Philippine context.

Taken together, the studies reported in this special issue, highlighted the roles that positive traits and states play in optimizing well-being, academic, and non-academic outcomes. The findings in each research directly contribute to the line of evidence on what desirable dispositions and states may potentially lead to a happy, meaningful, and successful life in ways that elaborate on established findings in the existing (but mostly Western) research literature. However, more investigations are warranted to further advance our understanding and application of the science of positive psychology in the Philippine setting. The articles featured in this special issue, together with the previous studies we cite in this introduction, will hopefully serve as a stimulus for further scientific research on this very broad area of study. As the studies featured and reviewed tended to focus on describing and testing theoretical models, future research should also venture into: (a) conceptualizing culturally-sensitive models of positive psychological concepts grounded from the unique experiences of Filipino populations; (b) evaluating the effectiveness of Western-derived positive psychological interventions and programs in the Philippine context; and (c) developing and testing positive psychological interventions that are premised on empirical concepts and findings based on Philippine research and adapted to Philippine realities. Positive psychology provides potentially useful tools for scientific understanding and interventions for psychologists in the Philippines, but it is imperative that Philippine psychologists further develop the knowledge base upon which positive psychology can thrive in the Philippines.

\section{REFERENCES}

Bernardo, A. B. I. (2013). Hope grounded in belief: Influences of reward for application and social cynicism on dispositional hope. Scandinavian Journal of Psychology, 54, 522-528.

Bernardo, A. B. I., Daganzo, M. A. A., \& Ocampo, A. C. G. (2016). Abusive supervision and well-being of Filipino migrant workers in Macau: Consequences for self-esteem and heritage culture attachment. Social Indicators Research. Advance online publication. doi: 10.1007/s11205-016-1446-7 
Bernardo, A. B. I., \& Estrellado, A. F. (2017a). Well-being of Filipino women who experienced intimate partner violence: A personcentered analysis. International Journal for the Advancement of Counselling, 39, 360-376.

Bernardo, A. B. I., \& Estrellado, A. F. (2017b). Locus-of-hope and helpseeking intentions of Filipino women victims of intimate partner violence. Current Psychology, 36, 66-75.

Bernardo, A. B. I., \& Fernando-Resurreccion, K. (2018). Financial stress and well-being of Filipino students: The moderating role of external locus-of-hope. Philippine Journal of Psychology, 51(1), $33-61$.

Bernardo, A. B. I., Salanga, M. G. C., Khan, A., \& Yeung, S. S. (2016). Internal and external loci-of-hope predict use of individual and collaborative learning strategies: Evidence from university students in four Asian cities. The Asia-Pacific Education Researcher, 25(3), 367-376.

Bernardo, A. B. I., Tan-Mansukhani, R., Daganzo, M. A. A. (in press). Associations between materialism, gratitude, and well-being in children of overseas Filipino workers. Europe's Journal of Psychology.

Buenconsejo, J. U. (2018). Sanctification of adolescence: A qualitative analysis if thriving among Filipino youth with religious sparks. Philippine Journal of Psychology, 51(1), 121-154.

Caleon, I. S. C., King, R. B., Tan, J. P.-L., Low, M., Tan, C. S., \& Liem, G. A. D. (2017). Nurturing grateful and connected twenty-first century learners: Development and evaluation of a socially-oriented gratitude intervention. Asia-Pacific Journal of Education, 37, 567-581.

Caleon, I. S., Wui, M. G. L., Chiam, C. L., King, R. B., Tan, J. P.-L., \& Tan, C. S. (2017). Shifting achievement trajectories: Personal strengths and perceived teacher support as predictors of Singapore students' academic risk status. Educational Psychology, 37, 9831000.

Chen, F., Bao, L., Shattuck, R. M., Borja, J. B., \& Gultiano, S. (2017). Implications of changes in family structure and composition for the psychological well-being of Filipino women in middle and later years. Research on Aging, 39(2), 275-299.

Church, A. T., Katigbak, M. S., Ibáñez-Reyes, J., de Jesús VargasFlores, J., Curtis, G. J., Tanaka-Matsumi, J., . . . \& Locke, K. D. (2014). Relating self-concept consistency to hedonic and eudaimonic well-being in eight cultures. Journal of CrossCultural Psychology, 45(5), 695-712.

Datu, J. A. D., \& Lizada, G. S. N. (2018). Interdependent happiness 
predicts behavioral and emotional engagement among Filipino university students. Philippine Journal of Psychology, 51(1), 6380.

Datu, J. A. D., \& Mateo, N. J. (2015). Gratitude and life satisfaction among Filipino adolescents: The mediating role of meaning in life. International Journal for the Advancement of Counselling, 37(2), 198-206.

Datu, J. A. D., \& Mateo, N. J. (2017). Work-related flow dimensions differentially predict anxiety, life satisfaction, and work longevity among Filipino counselors. Current Psychology, 36(2), 203-208.

Datu, J. A. D., King, R. B., \& Valdez, J. P. M. (2016). The benefits of socially-oriented happiness: Validation of the interdependent happiness scale in the Philippines. Child Indicators Research, 9(3), 631-649.

Datu, J. A. D., King, R. B., \& Valdez, J. P. M. (2017). The academic rewards of socially-oriented happiness: Interdependent happiness promotes academic engagement. Journal of School Psychology, 61, 19-31.

Datu, J. A. D., King, R. B., \& Valdez, J. P. M. (2018). Psychological capital bolsters motivation, engagement, and achievement: Cross-sectional and longitudinal studies. The Journal of Positive Psychology, 13(3), 260-270.

Datu, J. A. D., King, R. B., Valdez, J. P. M., \& Eala, M. S. M. (2018). Grit is associated with lower depression via meaning in life among Filipino high school students. Youth \& Society. Advance online publication. doi:10.1177/0044118X18760402.

Datu, J. A. D., \& Valdez, J. P. M. (2016). Psychological capital predicts academic engagement and well-being in Filipino high school students. The Asia-Pacific Education Researcher, 25(3), 399-405.

Datu, J. A. D., Valdez, J. P., Cabrera, I. K., \& Salanga, M. G. (2017). Subjective happiness optimizes educational outcomes: Evidence from Filipino high school students. Spanish Journal of Psychology. Advance online publication. doi:10.1017/sjp.2017.55

De Guzman, A. B., Largo, E., Mandap, L., \& Muñoz, V. M. (2014). The mediating effect of happiness on the job satisfaction of aging Filipino workers: A structural equation model (SEM). Educational Gerontology, 4O(10), 767-782.

De Guzman, A. B., Silva, K. E. M., Silvestre, J. Q., Simbillo, J. G. P., Simpauco, J. J. L., Sinugbuhan, R. J. P., . . \& Siy, M. R. C. (2012). For your eyes only: A Q-methodology on the ontology of happiness among chronically ill Filipino elderly in a penal institution. Journal of Happiness Studies, 13(5), 913-930.

Duan, W., Ho, S. M., Tang, X., Li, T., \& Zhang, Y. (2014). Character 
strength-based intervention to promote satisfaction with life in the Chinese university context. Journal of Happiness Studies, 15(6), 1347-1361.

Edillo, M. T. A., Turiano, M. K., Reyes, J. A. S., \& Villanueva, C. L. J. (2012). The mediating role of social comparison in the relationship between choice-making orientation and subjective well being. Philippine Journal of Counseling Psychology, 14(1), $13-28$.

Ganotice, F. A., Yeung, S. S., Beguina, L. A., \& Villarosa, J. B. (2016). In search for hero among Filipino teachers: The relationship of positive psychological capital and work-related outcomes. The Asia-Pacific Education Researcher, 25(3), 407-414.

Graham, E., \& Jordan, L. P. (2011). Migrant parents and the psychological well-being of left-behind children in Southeast Asia. Journal of Marriage and Family, 73(4), 763-787.

Guevara, C. C. A. (2016). Life satisfaction among older Filipino sexual minorities and their experiences of support. Philippine Journal of Psychology, 49(2), 135-155.

Joshanloo, M. (2014). Eastern conceptualizations of happiness: Fundamental differences with Western views. Journal of Happiness Studies, 15(2), 475-493.

Joshanloo, M., \& Weijers, D. (2014). Aversion to happiness across cultures: A review of where and why people are averse to happiness. Journal of Happiness Studies, 15(3), 717-735.

King, R. B. (2015). Sense of relatedness boosts engagement, achievement, and well-being: A latent growth model study. Contemporary Educational Psychology, 42, 26-38.

King, R. B., Caleon, I. S., Tan, J. P. L., \& Ye, S. (2016). Positive education in Asia. The Asia Pacific Education Researcher, 25(3), 361-365.

King, R. B., \& Datu, J. A. (2017). Happy classes make happy students: Classmates' well-being predicts individual student wellbeing. Journal of School Psychology, 65, 116-128.

Kumano, M. (2018). On the concept of well-being in Japan: Feeling shiawase as hedonic well-being and feeling ikigai as eudaimonic well-being. Applied Research in Quality of Life, 13, 419-433.

Kuppens, P., Realo, A., \& Diener, E. (2008). The role of positive and negative emotions in life satisfaction judgment across nations. Journal of Personality and Social Psychology, 95(1), 6675 .

Low, M., King, R. B., \& Caleon, I. S. (2016). Positive emotions predict students' well-being and academic motivation: The broadenand-build approach. In R. B. King \& A. B. I. Bernardo (Eds.), The psychology of Asian learners (pp. 485-501). Singapore: Springer. 
Magno, C., Galang, M. J. A., Paterno, V. C., \& Roldan, A. E. (2011). Meaning in life, flow, and subjective well-being: A perspective on Filipino high school students. Philippine Journal of Counseling Psychology, 13(1), 29-45.

Manalastas, E. J., \& Mondragon, A. V. (2006). Are you happy now? Agreement of self-father and mother-reports on judgments of life satisfaction of Filipino college students. Philippine Journal of Psychology, 39(1), 20-41.

Mateo, N. J., \& Salanga, M. G. C. (2018). Life satisfaction predicts positive workplace outcomes among Filipino guidance counselors. Philippine Journal of Psychology, 51(1), 81-99.

McGrath, R. E. (2015). Character strengths in 75 nations: An update. The Journal of Positive Psychology, 10, 41-52.

Mesurado, B., Richaud, M. C., \& Mateo, J. N. (2016). Engagement, flow, self-efficacy, and eustress of University Students: A crossnational comparison between the Philippines and Argentina. The Journal of Psychology, 15o(3), 281-299.

Nalipay, M. J. N., \& Alfonso, M. K. S. (2018). Career and talent development self-efficacy of Filipino students: The role of selfcompassion and hope. Philippine Journal of Psychology, 51(1), 101-120.

Nalipay, M. J. N., Bernardo, A. B. I., \& Mordeno, I. G. (2016). Social complexity beliefs predict posttraumatic growth in survivors of a natural disaster. Psychological Trauma: Theory, Research, Practice, and Policy, 8, 559-567.

Nalipay, M. J. N., Bernardo, A. B. I., \& Mordeno, I. G. (2017). Posttraumatic growth in survivors of a natural disaster: The role of the social axioms of religiosity, reward for application, and social cynicism. The Journal of Positive Psychology, 12, 342-353.

Redoble-Buot, N. G. (2006). Perceived discrimination, collective selfesteem, social support, locus of control and well-being of MNLF integrees. Philippine Journal of Psychology, 39(2), 153-180.

Resurreccion, R. R. (2017). A survey of character strengths of Filipinos using VIA-IS Filipino version. Philippine Journal of Counseling Psychology, 19(1), 81-94.

Rosopa, P. J., Datu, J. A. D., Robertson, S. A., \& Atkinson, T. P. (2016). Core self-evaluations and subjective well-being in the US and the Philippines: The moderating role of self-construal. Scandinavian Journal of Psychology, 57, 50-56.

Steel, P., Taras, V., Uggerslev, K., \& Bosco, F. (2017). The happy culture: A theoretical, meta-analytic, and empirical review of the relationship between culture and wealth and subjective wellbeing. Personality and Social Psychology Review, 22, 128-169. 
Swami, V., Stieger, S., Voracek, M., Dressler, S. G., Eisma, L., \& Furnham, A. (2009). Psychometric evaluation of the Tagalog and German Subjective Happiness Scales and a cross-cultural comparison. Social Indicators Research, 93(2), 393-406.

SyCip, L., Asis, M. M. B., \& Luna, E. (2000). The measurement of Filipino well-being. Quezon City: University of the Philippines, Center for Integrative Development Studies.

Tarroja, M. C. H., Balajadia-Alcala, M. A., \& Co, S. (2007). The impact of family composition and last incident of abuse on the psychosocial well-being of abused children. Philippine Journal of Psychology, 4O(2), 111-136.

Tov, W., \& Diener, E. (2009). Culture and subjective well-being. In E. Diener (Ed.) Culture and well-being (pp. 9-41). Dordrecht, Netherlands: Springer.

Tsai, J. L. (2007). Ideal affect: Cultural causes and behavioral consequences. Perspectives on Psychological Science, 2(3), 242259.

Uchida, Y., Kitayama, S., Mesquita, B., Reyes, J. A. S., \& Morling, B. (2008). Is perceived emotional support beneficial? Well-being and health in independent and interdependent cultures. Personality and Social Psychology Bulletin, 34(6), 741-754.

Villavicencio, F. T., \& Bernardo, A. B. I. (2016). Beyond math anxiety: Positive emotions predict mathematics achievement, self-regulation, and self-efficacy. The Asia-Pacific Education Researcher, 25(3), 415-422. 


\title{
REVIEWERS FOR THE \\ SPECIAL SECTION ON POSITIVE PSYCHOLOGY RESEARCH IN THE PHILIPPINES
}

\author{
Wai Tsz Ricci Fong \\ The Education University of Hong Kong \\ Fraide A. Ganotice \\ Hong Kong Shue Yan University \\ Nino Jose Mateo \\ De La Salle University \\ Ma. Jenina N. Nalipay \\ Philippine Normal University \\ Alfred Presbitero \\ Deakin University
}

